\title{
Methods and Models for Risk Analysis of External Unlawful Acts at Oil and Gas Facilities
}

\author{
Valery Lesnykh, Alexander Bochkov \\ LLC Gazprom gaznadzor, Moscow, Russia
}

doi: https://doi.org/10.21467/abstracts.93.103

\begin{abstract}
The experience of last decades shows that the share of losses of producer companies is increasing in the world because of actions of international organized criminal groups. This threat mainly touches on politically unstable regions, however a perspective development of a fuel and energy complex (FEC) different countries raise new demands to safety and functioning reliability of FEC objects and, first of all, objects of oil and gas industry. The primary objective of any protection system is finding and prevention of attempts of commitment of illegal actions concerning property of physical persons and information. The so-called principle of acceptable equal risk included in supply of security of oil and gas objects located in the high sea and on off-shore at the level defined from a condition equal (with other objects) for the proprietor of risk of its destruction (the functioning termination) is put in a basis of the technical approach offered in the paper.

By risk, we mean a probable damage (negative consequences) for the state and the proprietor of the objects, come out due to illegal actions concerning considered object. This risk is characterized by product probability of achievement of the purpose of illegal actions (index of object vulnerability) on the average damage caused by these actions. The factor of risk of illegal actions on sea and offshore oil and gas objects is the basic factor of efficiency of realization of the actions directed on supply of their protection.

When considering diversions concerning modern technological objects statistics methods are little applicable: purposeful character of actions, presence of huge number of purposes, specificity of a situation, awareness of infringers don't allow somehow to predict place, time, character and scale of the next action. Moreover, infringers "study", accumulate experience of carrying out of successful/unsuccessful operations, and, thereby, don't repeat the errors and inefficient actions made by them (so-called intellectual terrorism). Considering it, happened deliberate actions should be considered only in the aspect of definition of existing character and possibility of definition of development trends. For example, from the fact, that infringers have spent rather limited number of actions against platforms, doesn't follow that in the long term during rather limited time series of actions against the given objects can't begin.

Owing to said, for forecasting of character and possible scales of losses from diversions the principle of «full pessimism» can be used at which it is considered that against considered objects all technical means and forces which are available for terrorists for carrying out of operations in the sea, off-shore and in ports can be used. Rating features on degree of potential danger should be based on prior estimation of full damage for the interested subject in case of destruction (or functioning terminations) considered objects as a result of illegal action which is carried out under the most adverse scenario. The comparative analysis of models of the infringer, with reference to exploration objects, allows allocating models of the following 4 types:

actions against sea stationary surface object to which actions in regard to production platforms, floating storages and ships for overloading of liquid hydrocarbons are considered;
\end{abstract}

C 2020 Copyright held by the author(s). Published by AIJR Publisher in "Abstracts of The Second Eurasian RISK-2020 Conference and Symposium" April 12- 19, 2020, Tbilisi, Georgia. Jointly organized by AMIR Technical Services LLC, Georgian Technical University, Institute of Geography (Kazakhstan) and Russian Institute of Petroleum Geology and Geophysics.

Aij. DOI: $10.21467 /$ abstracts.93 
The Second Eurasian RISK-2020 Conference and Symposium

actions against sea mobile surface object including actions concerning tankers for transportation of liquid hydrocarbons;

actions against sea stationary subsea object, including actions concerning subsea production complexes, underwater sea transfer and off-shore pipelines;

actions against shore stationary object located at shoreline - shore-based terminals.

At the same time, it is clear that to organize effective diversion in a surface part of sea object or the object located in offshore zone, is extremely difficult. The operation can be easily disclosed at a preparation stage. Besides, a damage from underwater diversion is order of magnitude greater than a damage from actions of diversionary group in a surface part of sea objects. A combination of secrecy of carrying out of underwater diversion with consequences (i.e. productivity) from its carrying out isn't comparable with any of other possible kinds of attack on sea objects. The complex of organizational arrangements providing set level of sea objects safety, should be developed at a stage of design assignment preparation and at preliminary design and should provide timely detection and absolute suppression of any unauthorized activity that is provided, in turn, with efficiency and resoluteness of sea objects safety system management.

Generally, classification of objects of arrangement by degree of risk of illegal actions is carried out with account of [1-3]:

results of classification by size of potential danger (cumulative damage from damage (destruction) of objects and their vulnerability to illegal actions;

structure of classified object;

probability of success of infringers at carrying out of diversions concerning object;

threat level in region of object placing;

preference of the given object for fulfillment diversions against it.

Classifications of objects by degree of risk of illegal actions allows establishing:

priority of objects protection;

objects of protection which are subject to primary protection.

Objects of protection of the first class on degree of external illegal actions risk need primary protection. The object class on probable consequences (risk) of terrorist actions is established by means of criteria of scale of probable consequences (risk) of terrorist actions concerning objects of protection. As a criterion parameter, standardized value of probable consequences (risk) of terrorist actions is used for which estimation the following things are necessary: the data of hierarchical classification of objects of protection; object classes on potential danger and terrorist vulnerability and model of infringer.

The value of negligible level of terrorist risk is defined from a condition of sufficiency of led arrangements on protection of objects depending, in its turn, from objects classes on potential danger.

As a result, purposes are differed according to their importance for infringer, depending on effect from fulfillment of illegal action reached on his assumptions.

\section{References}

1. Ushakov, I.A., et al. (2007). Analysis of the Risk of Terrorist Attacks: the Use of Minimax Criterion, Strahovoyedelo, No. 3-4.

2. Radaev, N.N., Bochkov A.V. (2008). Assessment of Terrorist Risk in Operation of Facilities, Proceedings of International Scientific School MABR - Modeling and Analysis of Safety and Risk in Complex Systems, St. Petersburg, 24-28 June 2008.

3. Ushakov I. Counter-terrorism: Protection Resources Allocation. e-Journal Reliability: Theory \& Applications (vol.1), No 2, 3, 4, 2006. 